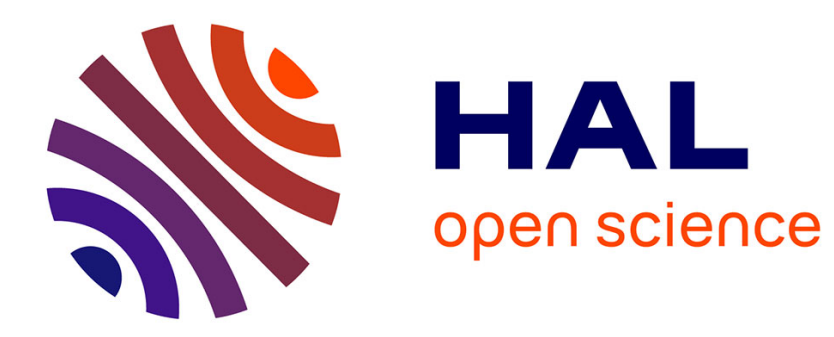

\title{
Seedling resistance to Phytophthora cinnamomi in the genus Abies
}

Frampton, D. Benson

\section{To cite this version:}

Frampton, D. Benson. Seedling resistance to Phytophthora cinnamomi in the genus Abies. Annals of Forest Science, 2012, 69 (7), pp.805-812. 10.1007/s13595-012-0205-4 . hal-00930854

\section{HAL Id: hal-00930854 https://hal.science/hal-00930854}

Submitted on 1 Jan 2012

HAL is a multi-disciplinary open access archive for the deposit and dissemination of scientific research documents, whether they are published or not. The documents may come from teaching and research institutions in France or abroad, or from public or private research centers.
L'archive ouverte pluridisciplinaire HAL, est destinée au dépôt et à la diffusion de documents scientifiques de niveau recherche, publiés ou non, émanant des établissements d'enseignement et de recherche français ou étrangers, des laboratoires publics ou privés. 


\title{
Seedling resistance to Phytophthora cinnamomi in the genus Abies
}

\author{
John Frampton • D. Michael Benson
}

Received: 2 January 2012 / Accepted: 18 March 2012 / Published online: 8 May 2012

(C) INRA / Springer-Verlag France 2012

\begin{abstract}
- Context Root rot and stem canker caused by Oomycete species belonging to the genus Phytophthora often seriously limit culture of true firs (Abies spp.)

- Aim An investigation of the variation of resistance among Abies species to Phytophthora cinnamomi was carried out to identify potential sources of resistance in the genus.

- Methods Thirty-two Abies species were grown in a greenhouse for 2 and/or 3 years from seed. Seedlings were moved to an outdoor lath house, inoculated with rice grains colonized with $P$. cinnamomi, and subsequent mortality was assessed biweekly for 16 weeks.

- Results Disease developed rapidly resulting in $88.1 \%$ overall mortality 16 weeks after inoculation. Mortality was less in two of the eight taxonomic sections of the genus evaluated, Momi $(0.65 \pm 0.0252)$ and Abies $(0.79 \pm 0.0193)$. Mortality in all other sections exceeded $93 \%$. Final species mortality ranged from $10.6 \%$ (Abies firma) to $100.0 \%$ (several species).

- Conclusions Although several caveats apply, results have identified potential sources of Abies to be used as (1) resistant planting stock, (2) grafting rootstock, and (3) parents in
\end{abstract}

\section{Handling Editor: Erwin Dreyer}

Contribution of the co-authors JF designed the experiment and both authors collaborated in conducting the experiment. JF performed the data analysis and led in writing the manuscript.

J. Frampton $(\bowtie)$

Department of Forestry \& Environmental Resources,

North Carolina State University,

Box 8008, Raleigh, NC 27695, USA

e-mail: frampton@ncsu.edu

D. M. Benson

Department of Plant Pathology, North Carolina State University, Raleigh, NC 27695, USA hybridization/backcrossing programs in order to mitigate losses caused by P. cinnamomi.

Keywords Abies · Fir P Phytophthora $\cdot$ Phytophthora cinnamomi $\cdot$ Host range $\cdot$ Root rot $\cdot$ Christmas trees $\cdot$ Disease resistance $\cdot$ Plant disease

\section{Introduction}

The true firs (Abies spp.) make up the second largest genus of the pine family (Pinaceae). Firs are medium to large coniferous trees typically narrowly pyramidal in shape with upright deciduous female cones that mature in one season. They occur mostly in temperate and frigid latitudes and higher elevations of the northern hemisphere. Fir taxonomy remains somewhat controversial partially due to intermediate forms among closely related species. Recently, taxonomists have described 39, 40, 45, 46, 49, or 55 Abies species worldwide (Eckenwalder 2009; Farjon 1990; Farjon and Rushforth 1989; Krüssmann 1995; Liu 1971; Rushforth 1987). Taxonomic names used herein (Table 1) follow the Farjon (1990) classification with three exceptions where the Krüssmann (1995) classification was employed: (1) Abies borisii-regii was considered a separate species rather than a hybrid between Abies alba $\times$ Abies cephalonica and (2) Abies bornmuelleriana as well as (3) Abies equi-trojani were considered separate species rather than one subspecies of Abies nordmanniana.

Although there are some notable exceptions, the firs as a group are not commercially important in the production of wood and pulp products, particularly in comparison to other conifers such as the spruces (Picea spp.) and pines (Pinus spp.). The oleoresin of firs is sometimes commercially used for medicinal purposes, as a medium for permanently 
Table 1 Least-squares means and standard errors for seedling mortality (proportion) of 32 Abies species from nine taxonomic sections 16 weeks after inoculation with Phytophthora cinnamomi

\begin{tabular}{|c|c|c|c|c|c|}
\hline Section & Mean & SE & Species & Mean & SE \\
\hline \multirow[t]{7}{*}{ Abies } & \multirow[t]{7}{*}{$0.7926 \mathrm{~d}$} & \multirow[t]{7}{*}{0.0193} & A. alba Mill. & 0.9177 & 0.0301 \\
\hline & & & A. borisii-regis Mattf. & 0.7577 & 0.0482 \\
\hline & & & A. bornmuelleriana Mattf. & 0.6169 & 0.6169 \\
\hline & & & A. cephalonica Loud. & 0.8341 & 0.0466 \\
\hline & & & A. cilicica (Ant. et Kotschy) Carrière & 0.6318 & 0.1128 \\
\hline & & & A. equi-trojani Aschers. and Sint. & 0.8497 & 0.0282 \\
\hline & & & A. nordmanniana (Steven) Spach & 0.8127 & 0.0188 \\
\hline $\begin{array}{l}\text { Amabilis (Matzenko) } \\
\text { Farjon and Rushforth }\end{array}$ & $0.9929 b c$ & 0.0071 & A. amabilis Dougl. ex Forbes & 0.9929 & 0.0071 \\
\hline \multirow{8}{*}{$\begin{array}{l}\text { Balsamea Engelm. emend. } \\
\text { Farjon and Rushforth }\end{array}$} & \multirow[t]{8}{*}{$0.9994 b$} & \multirow[t]{8}{*}{0.0002} & A. balsamea (L.) Mill. & 0.9867 & 0.0044 \\
\hline & & & A. fraseri (Pursch) Poir. & 1.0000 & 0.0000 \\
\hline & & & A. koreana Wilson & 0.9942 & 0.0058 \\
\hline & & & A. lasiocarpa (Hook.) Nutt. & 0.9882 & 0.0083 \\
\hline & & & A. nephrolepis (Trautv. Ex Maxim.) Maxim. & 1.0000 & 0.0000 \\
\hline & & & A. sachalinensis (Fr. Schmidt) Masters & 0.9318 & 0.0477 \\
\hline & & & A. sibirica Ledeb. & 0.6941 & 0.0521 \\
\hline & & & A. veitchii Lindl. & 0.9942 & 0.0058 \\
\hline $\begin{array}{l}\text { Bracteata Engelm. } \\
\text { emend. Sargent }\end{array}$ & $0.9708 \mathrm{c}$ & 0.0129 & A. bracteata (D. Don) D. Don ex Poit. & 0.9708 & 0.0129 \\
\hline \multirow{3}{*}{$\begin{array}{l}\text { Grandis Engelm. emend } \\
\text { Farjon and Rushforth }\end{array}$} & \multirow[t]{3}{*}{$0.9390 \mathrm{c}$} & \multirow[t]{3}{*}{0.0204} & A. concolor (Gord. and Glend.) Lindl. ex Hildebr. & 0.8510 & 0.0280 \\
\hline & & & A. grandis (Dougl. ex D. Don) Lindl. & 0.9849 & 0.0150 \\
\hline & & & A. guatemalensis Rehder & 0.9073 & 0.0231 \\
\hline \multirow[t]{5}{*}{ Momi Franco } & \multirow[t]{5}{*}{$0.6554 \mathrm{e}$} & \multirow[t]{5}{*}{0.0252} & A. chensiensis Van Tieghem & 0.8322 & 0.0367 \\
\hline & & & A. firma Sieb. and Zucc. & 0.1064 & 0.0240 \\
\hline & & & A. holophylla Maxim. & 0.8936 & 0.0240 \\
\hline & & & A. pindrow (D. Don) Royle & 0.2931 & 0.0364 \\
\hline & & & A. recurvata Masters & 0.9237 & 0.0206 \\
\hline \multirow[t]{2}{*}{ Nobilis Engelm. } & \multirow[t]{2}{*}{$1.000 \mathrm{a}$} & \multirow[t]{2}{*}{$5.8600 \mathrm{E}-06$} & A. magnifica Andr. Murray & 1.0000 & 0.0000 \\
\hline & & & A. procera Rehder & 0.9761 & 0.0097 \\
\hline $\begin{array}{l}\text { Piceaster Spach. emend. } \\
\text { Farjon and Rushforth }\end{array}$ & $0.9768 \mathrm{c}$ & 0.0163 & A. numidica De Lannoy ex Carrière & 0.9768 & 0.0163 \\
\hline \multirow{4}{*}{$\begin{array}{l}\text { Pseudopicea Hickel emend. } \\
\text { Farjon and Rushforth }\end{array}$} & \multirow[t]{4}{*}{$0.9646 \mathrm{c}$} & \multirow[t]{4}{*}{0.0102} & A. delavayi Franch. & 0.9592 & 0.9592 \\
\hline & & & A. fabri (Masters) Craib & 0.9117 & 0.0220 \\
\hline & & & A. fargesii Franch. & 0.9296 & 0.0279 \\
\hline & & & A. forestii C. Coltm. Rogers. & 0.9942 & 0.0058 \\
\hline
\end{tabular}

In the means section, values followed by the same letter are not significantly different $(p<0.5)$ according to the Tukey-Kramer multiple range test

mounting microscope slides and for cementing components of optical systems (Burns and Honkala 1990; Harlow and Harrar 1969; van Gelderen and van Hoey Smith 1995). Firs are beautiful trees in their natural habitat but their role as ornamentals is not prominent. Nevertheless, prostrate, compact, pendulous, and blue-foliage cultivars (over 150 total) have been developed that can add novel and beautiful textures, colors, and shapes to residential landscapes (van Gelderen and van Hoey Smith 1995).

Firs are ideally suited for use as Christmas trees due to their natural conical shape, pleasant color and aroma, and strong branches for holding ornaments. Additionally, many fir species have excellent needle retention ability allowing them to be harvested and shipped weeks before their use in consumers' homes. Annual Christmas tree use exceeds 30 million in North American and 50 million in Europe (Chastagner and Benson 2000).

Some of the most serious diseases afflicting fir Christmas tree production are Phytophthora root rot and stem canker (Chastagner and Benson 2000). The Phytophthora species associated with disease of fir varies with host species and region but include Phytophthora cactorum (Leb. and Cohn) 
Schröeter, Phytophthora cinnamomi Rands, Phytophthora citricola Sawada sensu lato, Phytophthora cryptogea Pethybridge and Lafferty, Phytophthora drechsleri Tucker, Phytophthora gonapodyides (Petersen) Buisman, Phytophthora megasperma Drechsler, and Phytophthora pseudotsugae Hamm and Hansen (Benson and Grand 2000; Benson et al. 1976; Chastagner 1997; Shew and Benson 1982).

In the Southern Appalachian region of the USA, cultivation of Abies fraseri (Fraser fir) as Christmas trees has developed into a significant industry over the last 40 years. In North Carolina alone, revenue from Christmas tree sales, largely A. fraseri, totalled US\$134 million in 2006 (Strickland 2007). Regionally, significant mortality occurs in many Christmas tree nurseries and plantations due to root rot disease caused primarily by $P$. cinnamomi (Chastagner and Benson 2000). While chemical methods are available for controlling this disease in seedling and transplant beds, chemical control in plantations is stop-gap at best (Benson et al. 2006). Severely infested sites must be abandoned, perhaps permanently, for $A$. fraseri cultivation. With climate change, the range of $P$. cinnamomi is expected to expand (Sturrock et al. 2011) increasing the threat to both Christmas tree production and natural fir stands.

Since genetic resistance is widely used to ameliorate impacts of diseases caused by Phytophthora spp. in agriculture and horticulture (Erwin and Ribeiro 1996), research has been carried out to identify resistant $A$. fraseri material by employing greenhouse inoculation trials. These trials confirmed experiences in highly infested Christmas tree plantations that $A$. fraseri is extremely susceptible to $P$. cinnamomi. Overall, mortality of $A$. fraseri seedlings in one greenhouse inoculation trial was $90 \%$ after 122 days but varied significantly among geographic seed sources (Frampton and Benson 2004). In another greenhouse inoculation trial, mortality of $100 \mathrm{~A}$. fraseri open-pollinated families from a single geographic source ranged from 91 to $100 \% 4$ months following inoculation with 42 families exhibiting $100 \%$ mortality (Frampton et al. 2003). Surviving seedlings from both of these studies eventually died, and in a follow-up study, all seedlings from 100 openpollinated families representing each of the six major geographic sources of $A$. fraseri died within 4 months of inoculation (Frampton and Benson 2003, unpublished data).

Given that these prior studies strongly suggest that little, if any, resistance to $P$. cinnamomi exists in young $A$. fraseri seedlings, an investigation of the variation of resistance among other Abies species was carried out. The results of this study successfully identified potential sources of resistance to $P$. cinnamomi in fir and ranked the relative resistance of many species in the Abies genus. Further, the large representation of the genus (about $70 \%$ of described species) yielded insight into taxonomic and global geographic patterns of variation in host resistance not discernible in previous investigations. These results will be of interest to plant pathologists, conifer taxonomists, and forest geneticists as well as tree breeders, forestry practitioners, and Christmas tree growers.

\section{Materials and methods}

\subsection{Plant production}

Seeds of Abies species were obtained, mostly from US vendors, and used to grow containerized seedlings of 50 sources representing 32 species. More than one source of several species were included: Abies balsamea (four provenances), A. fraseri (three provenances), Abies magnifica (two provenances), A. nordmanniana (four provenances plus eight open-pollinated families from a Romanian plantation), and Abies procera (two provenances). Species represented all of the taxonomic sections recognized by Farjon (1990) except Section Oiamel Franco.

Seeds were stratified and then sown in April of 2000 and 2001 into fine vermiculite in a greenhouse in Raleigh, NC, USA. Thirty-two sources representing 24 species were grown in both years while 7 and 13 sources were grown only in 2000 and 2001, respectively. Germinating seedlings were transplanted into a 1:1 $(v / v)$ mixture of peat and perlite in Ray Leach Pine Cells $\left(66 \mathrm{~cm}^{3}\right.$, Stuewe and Sons, Inc., Corvallis, OR, USA). Depending on seed availability and germination, as many as 20 germinants per seedlot were transplanted into each of four randomized blocks in the greenhouse. The seedlings were fertilized weekly with Peters 15-16-17 Peat Lite Special (150-200 ppm N) (J.R. Peters, Allentown, PA, USA) and treated with insecticides as needed. The photoperiod was extended to $16 \mathrm{~h}$ from August through October by placing 1,000 W halide lamps on a $3-\mathrm{m}$ grid $1.4 \mathrm{~m}$ above the trees. The supplemental light was discontinued in November and the thermostat was set to $4{ }^{\circ} \mathrm{C}$ to induce winter dormancy. During the summer of 2003, the seedlings were moved from the greenhouse for inoculations. Following inoculation, they were moved into an outdoor lath house and automatically irrigated twice daily (about $23 \mathrm{~mm} /$ day) completely saturating the medium.

\subsection{Inoculum production and inoculation}

One single genotype isolate (23ss 04$)$ of $P$. cinnamomi originally derived from $A$. fraseri was utilized. Inoculum was prepared by transferring three to four corn agar medium disks of the isolate to Erlenmeyer flasks containing $25 \mathrm{~g}$ of long-grain rice and $18 \mathrm{ml}$ of deionized water (Holmes and Benson 1994). The flasks containing rice grains and water had been autoclaved on two consecutive days prior to use. 
Cultures were shaken by hand daily to avoid clumping of the rice grains as mycelia colonized the grains. Colonization of rice grains by P. cinnamomi was $100 \%$ and the cultures were used between 7 and 10 days after preparation. During the summer of 2004, the seedlings were inoculated by making two holes about $2 \mathrm{~cm}$ deep and $1 \mathrm{~cm}$ from opposite sides of the seedling stem with a glass rod; then, placing a single colonized rice grain into each hole (Benson et al. 1997). The medium was pushed back to cover the inoculum. Eight weeks after the original inoculation, all live seedlings were re-inoculated in the same manner using the same isolate as in the original inoculation.

\subsection{Experimental design}

Prior to inoculation, four blocks that had been maintained during greenhouse culture were slightly reconfigured as necessary to balance the number of seedlings of each source across blocks. Each source was represented by up to 20 seedlings per block. At inoculation, each source of the 2year-old material was represented by 19 to 80 seedlings for a total of 3,258 seedlings, while each source of the 3-year-old material was represented by 20 to 80 seedlings for a total of 2,856 seedlings. Two blocks were inoculated in June and two on July 2004.

\subsection{Data collection and analyses}

Seedling heights were measured prior to inoculation. Seedling mortality (completely necrotic shoot) was assessed biweekly eight times after the initial inoculation. The probability of mortality of a single seedling 16 weeks after inoculation was modeled with the following fixed effects generalized linear model using a logit link function (i.e., a logistic regression model):

$$
\begin{aligned}
\eta_{i j k l}=\log [\pi /(1-\pi)]= & \mu+R_{i}+A_{j}+S_{k}+A_{j} S_{k} \\
& +\operatorname{Sp}(S)_{l(k)}+\operatorname{ASp}(S)_{i l(k)} \\
& +e_{i j k l}
\end{aligned}
$$

where $\eta_{i j k l}$ is the link function $[g(\mu)], \mu$ is the conditional mean, $\pi$ is the proportion of dead seedlings, $R_{i}$ is the effect of the $i$ th block, $A_{j}$ is the effect of the $j$ th age, $S_{k}$ is the effect of the $k$ th taxonomic section, $A_{j} S_{k}$ is the interaction effect between the $j$ th age and the $k$ th taxonomic section, $S p(S)_{l(k)}$ is the effect of the $l$ th species in the $k$ th taxonomic section, $A S p(S)_{i l(k)}$ is the interaction between the $j$ th age and the $l$ th species within the $k$ th taxonomic section, and $e_{i j k l}$ is the random residual $\sim \mathrm{N}\left(0, I \sigma_{\mathrm{e}}{ }^{2}\right)$. This model was executed using the GLMMIX procedure of SAS/STAT software (SAS 2009 ) and only included the 24 species (32 sources) that were represented by both ages. Because age and its interactions with taxonomic section and species were not significant ( $p=0.9816,0.2012$, and 0.2909 , respectively) in this analysis, these terms were dropped from the model and a reduced model was run including all sources (except for the eight open-pollinated $A$. nordmanniana families):

$\eta_{i j k l}=\log [\pi /(1-\pi)]=\mu+R_{i}+S_{k}+\operatorname{Sp}(S)_{l(k)}+e_{i j k l}$.

To investigate within-species variation, separate analyses were conducted for the five species represented by more than one source employing the following model:

$\eta_{i j k l}=\log [\pi /(1-\pi)]=\mu+R_{i}+T_{j}+e_{i j k}$

where $T_{j}$ is the effect of the $j$ th source (provenance or openpollinated family) and other terms are as defined in Eq. (1). For A. nordmanniana, this model was run twice, first for the four provenances, and then for the eight open-pollinated families.

Reported least-squares means and standard error estimates were converted from the logit scale by applying the inverse link function:

$\pi=1 /(1+\exp (-\eta))$

Mortality curves for each species were developed to investigate differences in rate of mortality. The biweekly mortality assessments were fit to the nonlinear Richards' function using maximum likelihood techniques with a conditional binary distribution:

$\delta=\alpha(1-\exp (-\beta t))^{c}$

where $\delta=$ mortality, $t=$ time in weeks and $\alpha, \beta$, and $c=$ equation coefficients. The $\alpha$ coefficient of Richards' function represents the upper asymptote of mortality. Together, the $\beta$ and $c$ coefficients of the Richards' function determine the shape of the growth curve between the $x$-axis and upper asymptote $(\alpha)$. From the estimated coefficients, the following additional parameters were calculated for each species:

$\mathrm{MR}=\mathrm{AB} /(2(2-1 / C))$

$\operatorname{MaxMR}=B(1-1 / C)$

$\operatorname{MR90}=2(2-1 / C) B$

where $A, B$, and $C=$ estimated coefficients, $\mathrm{MR}=$ weighted mean mortality rate (proportion/week), MaxMR=relative mortality rate at inflection point, i.e., where absolute mortality rate is maximum (proportion/week), and MR90 = time required to attain $90 \%$ of final mortality (weeks).

Midpoints for each species' geographic range were estimated by averaging the most northern and southern latitudes 
as well as the most eastern and western longitudes reported in the literature (Krüssmann 1995; Liu 1971). Using the midpoint latitude and longitude values, the distance along both great-circle and loxodrome (rhumb) lines from each species to the approximate geographic coordinates of Sumatra $\left(0.58^{\circ} \mathrm{S}, 101.37 \mathrm{E}\right)$ were calculated. Sumatra coordinates were chosen to approximate the point of origin of $P$. cinnamomi (Zentmyer 1988). A midpoint elevation for each species was also estimated by averaging high and low elevations from published ranges. Pearson correlation coefficients were calculated between the great-circle distance, loxodrome distance, latitude, longitude, elevation, and measures of mortality: final mortality lsmean, $A, B, C$, MR, MaxMR, and MR90. Additionally, the correlation between species initial height and final mortality was calculated.

\section{Results}

Root rot disease developed rapidly after inoculation (Fig. 1) resulting in $88.1 \%$ overall final (16 weeks following initial inoculation) mortality. Blocks, taxonomic sections, and species within sections were significantly different for final mortality $(p<0.0001)$. While block effects were significant, the range in mortality among blocks was small, about $1.1 \%$. Sect. Momi followed by Sect. Abies had significantly less mortality, 65.5 and $79.3 \%$, respectively, than the other sections, all of which exceeded $93 \%$ mortality (Table 1 ). Mortality differences among species were large ranging from $10.6 \%(A$. firma) to $100.0 \%$ (several species) (Table 1). However, no significant differences were found among provenances for the five species represented by more than one provenance. Variation among the eight open-pollinated families of $A$. nordmanniana was significant $(p<0.0001)$.

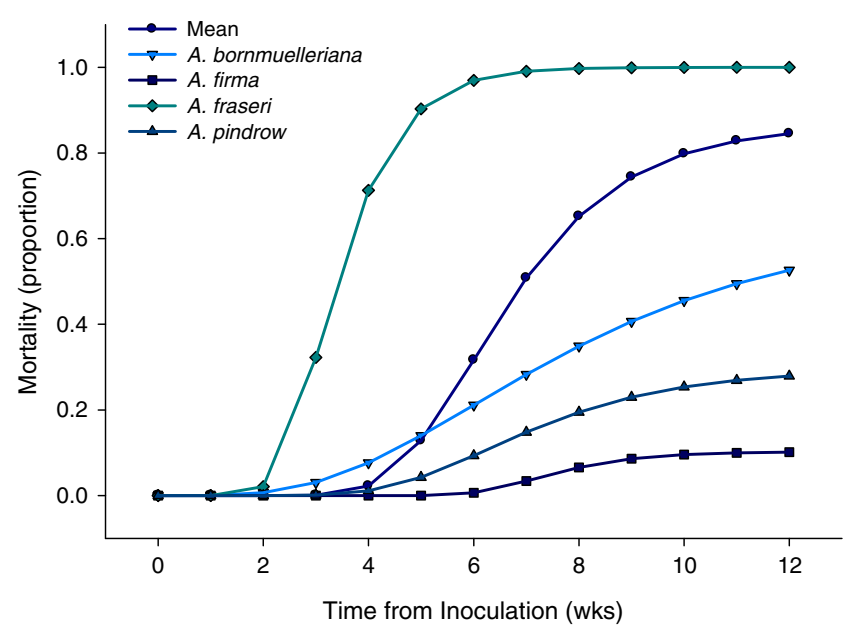

Fig. 1 Mortality curves for fir seedlings inoculated with P. cinnamomi. Seedling mortality was assessed biweekly for 16 weeks after inoculation. Curves are for the overall mean and four species selected to represent a range of resistance
Seedling height averaged $9.2 \mathrm{~cm}$ prior to inoculation. Although the average species height varied widely from $4.8 \mathrm{~cm}$ (A. cephalonica) to $21.6 \mathrm{~cm}$ (Abies guatemalen$s i s)$, it was not correlated with final mortality $(r=0.13$, $p=0.4669$ ).

Estimated parameters of Richards' function revealed considerable variation in mortality curves among species (Table 2). Estimates of the upper asymptote of the mortality curve ( $A$ parameter) approximated the final mortality of each species $(r=0.99, p>|r|<0.0001)$. The overall mean (MR) and maximum (MaxMR) mortality rates were estimated to be 14.4 and $68.0 \%$ /week (Table 3). Mean mortality rates (MR) varied considerably from $2.4 \% /$ week $(A$. firma) to $30.3 \%$ for (A. fraseri). The overall time to $90 \%$ mortality (MR90) was estimated be 7.2 weeks but ranged from 3.3 weeks (A. fraseri) up to 20.8 weeks (Abies cilicica).

Both loxodrome and great-circle distances of species' ranges from Sumatra were significantly and positively correlated with the estimated $B$ parameter of Richards' function $(r=0.43$ and 0.38 , respectively), the mean mortality rate $(r=$ 0.51 and 0.47 , respectively), and the maximum mortality rate $(r=0.41$ and 0.35 , respectively) (Table 4). Species' range mid-elevations were not significantly correlated with any measure of mortality (Table 4).

\section{Discussion}

\subsection{Patterns of variation in resistance}

Generally, the Abies genus was susceptible to mortality caused by P. cinnamomi although some variation was found. Taxonomic section and species rankings within the genus were based on the frequency of resistant (surviving) seedlings after inoculation with $P$. cinnamomi. The most resistant species, $A$. firma, also was ranked most resistant in an earlier resistance screening trial involving only six Abies species (Benson et al. 1997). This species is the type species for Sect. Momi, which ranked as the most resistant taxonomic section. This section includes Abies pindrow, the second most resistant species, but also some susceptible species. Sect. Abies included species that were susceptible to moderately resistant. Species from all other taxonomic sections evaluated were susceptible or very susceptible to mortality caused by $P$. cinnamomi.

Geographically, resistance in the Abies genus appeared largely to originate from eastern and central Asia and from the Mediterranean Sea region. All North American Abies species were susceptible. Perhaps, this geographic distribution of resistance reflects past contact during the evolutionary history of some Abies species with $P$. cinnamomi whose present-day native range is believed to be Southeast Asia (Erwin and Ribeiro 1996). Specifically, Zentmyer (1988) 
Table 2 Richards' function parameter estimates and standard errors
The $A$ coefficient represents the upper asymptote of mortality and estimates are similar to 16 -week mortalities reported in Table 1. Together, the $B$ and $C$ coefficients determine the shape of the growth curve between the $x$-axis and upper asymptote $(A)$

\begin{tabular}{|c|c|c|c|c|c|c|}
\hline \multirow[b]{2}{*}{ Species } & \multicolumn{3}{|c|}{ Parameter estimate } & \multicolumn{3}{|c|}{ SE of estimate } \\
\hline & $A$ & $B$ & $C$ & $A$ & $B$ & $C$ \\
\hline A. alba & 0.9014 & 0.5751 & 24.2254 & 0.0234 & 0.0865 & 11.4261 \\
\hline A. amabilis & 0.9936 & 0.8121 & 25.4123 & 0.0038 & 0.0653 & 7.3756 \\
\hline A. balsamea & 0.9787 & 0.9875 & 20.0522 & 0.0028 & 0.0427 & 2.7189 \\
\hline A. borisii-regis & 0.7495 & 0.3814 & 12.0672 & 0.0528 & 0.0835 & 5.9096 \\
\hline A. bornmuelleriana & 0.6332 & 0.2832 & 5.4370 & 0.0522 & 0.0600 & 1.7140 \\
\hline A. bracteata & 0.9801 & 0.5108 & 10.0668 & 0.0077 & 0.0357 & 1.8277 \\
\hline A. cephalonica & 0.8334 & 0.4746 & 7.4306 & 0.0308 & 0.0866 & 2.8268 \\
\hline A. chensiensis & 0.8277 & 0.4377 & 10.5725 & 0.0305 & 0.0684 & 3.8060 \\
\hline A. cilicica & 0.7914 & 0.1521 & 2.4048 & 0.3809 & 0.1425 & 1.7362 \\
\hline A. concolor & 0.8546 & 0.5712 & 42.1479 & 0.0194 & 0.0558 & 14.7078 \\
\hline A. delavayi & 0.9614 & 0.5703 & 11.2124 & 0.0090 & 0.0434 & 2.2686 \\
\hline A. equi-trojani & 0.8828 & 0.3163 & 6.1596 & 0.0330 & 0.0389 & 1.3342 \\
\hline A. fabri & 0.9208 & 0.4815 & 13.0513 & 0.0157 & 0.0437 & 3.1409 \\
\hline A. fargesii & 0.9387 & 0.4900 & 11.0379 & 0.0186 & 0.0591 & 3.4123 \\
\hline A. firma & 0.1028 & 0.9121 & 655.7676 & 0.0138 & 0.4370 & $1,827.3880$ \\
\hline A. forestii & 0.9949 & 0.6713 & 11.7335 & 0.0037 & 0.0479 & 2.4111 \\
\hline A. fraseri & 1.0000 & 1.1960 & 40.3411 & - & 0.0491 & 6.7887 \\
\hline A. grandis & 0.9863 & 0.8834 & 44.5981 & 0.0077 & 0.1275 & 26.6294 \\
\hline A. guatemalensis & 0.8990 & 0.4748 & 11.8774 & 0.0194 & 0.0535 & 3.3432 \\
\hline A. holophylla & 0.9061 & 0.4085 & 6.0932 & 0.0179 & 0.0407 & 1.2033 \\
\hline A. koreana & 0.9953 & 0.7761 & 20.7521 & 0.0030 & 0.0528 & 4.8057 \\
\hline A. lasiocarpa & 0.9894 & 0.9770 & 24.9138 & 0.0038 & 0.0716 & 6.3970 \\
\hline A. magnifica & 1.0000 & 0.8668 & 22.0826 & - & 0.0403 & 3.5779 \\
\hline A. nephrolepis & 0.9974 & 0.7134 & 9.1225 & 0.0025 & 0.0523 & 1.7850 \\
\hline A. nordmanniana & 0.8192 & 0.3332 & 4.5860 & 0.0181 & 0.0282 & 0.6202 \\
\hline A. numidica & 0.9762 & 0.5398 & 17.4789 & 0.0138 & 0.0633 & 6.2247 \\
\hline A. pindrow & 0.2946 & 0.5046 & 23.2134 & 0.0243 & 0.1214 & 15.4647 \\
\hline A. procera & 0.9644 & 1.0577 & 163.2944 & 0.0063 & 0.0808 & 61.7776 \\
\hline A. recurvata & 0.9281 & 0.4394 & 7.1539 & 0.0153 & 0.0406 & 1.4168 \\
\hline A. sachalinensis & 0.8819 & 1.0096 & 119.1157 & 0.0376 & 0.3786 & 201.8780 \\
\hline A. siberica & 0.6786 & 0.6649 & 14.5839 & 0.0264 & 0.1254 & 7.2649 \\
\hline A. veitchii & 0.9942 & 0.7356 & 7.2274 & 0.0034 & 0.0613 & 1.5082 \\
\hline
\end{tabular}

Table 3 Summary statistics for predicted mortality, weighted mean mortality rate (MR), relative mortality rate at inflection point (MaxMR), and time required to attain $90 \%$ of final mortality (MR90) for 32 Abies species

Mean Standard Minimum Maximum error

\begin{tabular}{lllll}
\hline $\begin{array}{l}\text { Predicted mortality } \\
\text { (proportion) }\end{array}$ & 0.86 & 0.0361 & 0.11 & 1.00 \\
MR (proportion/week) & 0.14 & 0.0127 & 0.02 & 0.30 \\
MaxMR (proportion/week) & 0.68 & 0.0429 & 0.26 & 1.23 \\
MR90 (week) & 7.21 & 0.6116 & 3.30 & 20.84 \\
\hline
\end{tabular}

MR, MaxMR, and MR90 were calculated from Richards' function parameter estimates (Table 2) using Eqs. 6, 7, and 8, respectively suggested that the area of origin of $P$. cinnamomi is most likely from New Guinea into Malaysia, particularly Sumatra, and possibly through Thailand extending into Taiwan. Estimates of the distance of species ranges from Sumatra were significantly and positively correlated with measures of species mortality supporting this hypothesis. Loxodrome distances, which represent constant bearing routes and appear as curves on the globe but lines on Mercator projection maps, had a stronger relationship to mortality parameters than did great-circle distances. Greatcircle distances represent the shortest distance between two points on the globe. However, for many species (e.g., $A$. fraseri), great-circle distances from the species range to Sumatra passed across the north polar region and, hence, 
Table 4 Pearson correlations between mortality parameters for 32 Abies species and the distance of their native range from the origin of Phytophthora cinnamomi (estimated by the approximate geographic coordinates of Sumatra)

Correlation (upper), $p>|r|$ (lower). Bold correlations are significantly different at $p<0.05$

\begin{tabular}{lllllllc}
\hline & Mortality & $A$ & $B$ & $C$ & MR & MaxMR & MR90 \\
\hline Mortality & 1.00 & $\mathbf{0 . 9 9}$ & 0.25 & $-\mathbf{0 . 6 1}$ & $\mathbf{0 . 7 1}$ & 0.28 & -0.31 \\
& 0.0000 & $<0.0001$ & 0.1649 & 0.0002 & $<0.0001$ & 0.1144 & 0.0812 \\
Loxodrome distance & 0.30 & 0.29 & $\mathbf{0 . 4 3}$ & -0.05 & $\mathbf{0 . 4 9}$ & $\mathbf{0 . 4 1}$ & -0.25 \\
& 0.0999 & 0.1049 & 0.0152 & 0.7745 & 0.0040 & 0.0191 & 0.1707 \\
Great-circle distance & 0.28 & 0.28 & $\mathbf{0 . 3 8}$ & -0.05 & $\mathbf{0 . 4 5}$ & $\mathbf{0 . 3 6}$ & -0.21 \\
& 0.1175 & 0.1212 & 0.0335 & 0.7687 & 0.0100 & 0.0422 & 0.2432 \\
Elevation & 0.09 & 0.10 & -0.26 & -0.27 & -0.13 & -0.26 & 0.09 \\
& 0.6156 & 0.5782 & 0.1543 & 0.1287 & 0.4785 & 0.1589 & 0.6141 \\
\hline
\end{tabular}

did not represent likely plant migration or pollen flow routes.

Alternatively, the geographic pattern of resistance in Abies may reflect (1) past or current exposure to other Oomycete species or (2) adaptation to particular environmental factors such as climate or soils that also affect resistance (pleiotropy). Experience with some of the resistant and intermediate species suggests that they tolerate poorly drained clayey soils and warm summer temperatures better than most Abies species (Frampton 2004).

No within-species variation for resistance was detected at the provenance level. Four of the five species represented by more than one geographic source were very susceptible so that provenance mortality ranged from 95 to $100 \%$. A. nordmanniana provided the best opportunity to examine within-species variation. Provenance differences for mortality were not significantly different but ranged from 75 (Borshomi) to $84 \%$ (northeast Turkey). However, differences in mortality of the eight open-pollinated families from a Romanian plantation were significant and ranged from 43 to $88 \%$. Thus, there appears to be more tree-to-tree variation within a geographic source than variation among sources for resistance as is often the case with other forest tree characteristics.

Within-species variation was not a primary objective of this study. Additional evaluation of the geographic distribution of resistant trees within a forest species of interest, particularly one classified as intermediate or resistant, is needed.

\subsection{Limitations}

Caution should be employed when interpreting the results of this investigation. First, the techniques used may have overlooked some types of resistance. Young seedlings were inoculated in this study which may not possess some resistance mechanisms active in older trees. Further, the conditions of this trial were different and more favorable for disease development than those under most field conditions because (1) a relatively large amount of inoculum was applied, (2) the medium was kept continuously wet, and (3) the root system was confined in the container. Another concern is the limited representation of each species. Species were only represented by one or a few provenances. Since many Abies species, such as Abies sibirica, have huge geographic ranges, results for a particular species may have been different had another or additional provenances been evaluated. Lastly, this investigation only employed a single isolate of $P$. cinnamomi. Interactions among Abies taxonomic sections or species and pathogen isolates could not be detected, and if they exist, they may have affected the results. Future research utilizing Abies sources identified in this study as potentially resistant or susceptible is needed to address host $\times$ pathogen genotype interactions.

\subsection{Implications}

Despite caveats, these results have helped identify likely sources of resistance in Abies. Both Christmas tree growers in the Southern Appalachian region and researchers are pursuing strategies to use knowledge produced by this study. Growers are experimenting with grafting $A$. fraseri onto rootstock of A. firma and Abies bornmuelleriana for planting in known Phytophthora-infested areas (HibbertFrey et al. 2010; Hinesley and Frampton 2002). Two recent cone collection expeditions to Turkey have resulted in the genetic resources to investigate within-species variation in A. bornmuelleriana and A. equi-trojani, not only for Phytophthora resistance, but also for adaptability, growth, and quality. Additionally, long-term hybridization and backcrossing efforts between $A$. fraseri and more resistant species have been initiated (Stejskal et al. 2011).

Acknowledgments We gratefully acknowledge the technical support of Anne Margaret Braham, Emily Hudson Heater, Jianfeng Li, and Kala Parker.

Funding This research was supported by the North Carolina Agricultural Research Service via the Christmas Tree Genetics Program and the U.S. Department of Agriculture (34458-14512). 


\section{References}

Benson DM, Grand LF (2000) Incidence of Phytophthora root rot of Fraser fir in North Carolina and sensitivity of isolates of Phytophthora cinnamomi to metalaxyl. Plant Dis 84:661-664

Benson DM, Grand LF, Suggs EG (1976) Root rot of Fraser fir caused by Phytophthora drechsleri. Plant Dis Rep 60:238-240

Benson DM, Hinesley LE, Frampton J, Parker KC (1997) Evaluation of six Abies spp. to Phytophthora root rot caused by Phytophthora cinnamomi. APS Biol Cult Tests 13:57

Benson DM, Sidebottom JR, Moody J (2006) Control of Phytophthora root rot in field plantings of Fraser fir with fosetyl-Al and mefenoxam. Online Plant Health Progress. doi:10.1094/PHP-20060331-01-RS

Burns RM, Honkala BH (1990) Silvics of North America. Volume 1, conifers. USDA For. Ser. Ag. Handbook 654. Washington DC. 675p

Chastagner GA (ed) (1997) Christmas tree diseases, insects, and disorders in the Pacific Northwest: identification and management. Washington State University Cooperative Extension, Pullman. $156 \mathrm{p}$

Chastagner GA, Benson DM (2000) The Christmas tree: traditions, production, and diseases. Online Plant Health Progress. doi:10.1094/PHP-2000-1013-01-RV

Eckenwalder JE (2009) Conifers of the world. Timber Press, Portland, p 720

Erwin DC, Ribeiro OK (1996) Phytophthora diseases worldwide. APS Press, St. Paul, p 562

Farjon A (1990) Pinaceae: drawings and descriptions of the genera Abies, Cedrus, Pseudolarix, Keteleeria, Nothotsuga, Tsuga, Cathaya, Pseudostuga, Larix and Picea. Koeltz Scientific Books, Konigstein, p 330

Farjon A, Rushforth KD (1989) A classification of Abies Miller (Pinaceae). Notes R Bot Garden Edinb 46:59-79

Frampton J (2004) Exotic fir research in North Carolina. Exotic Conifer News 14:5-8

Frampton J, Benson DM (2004) Phytophthora root rot mortality in Fraser fir seedlings. HortSci 39:1025-1026
Frampton J, Benson DM, Hinesley LE, Li J (2003) Developing Christmas trees resistant to Phytophthora root rot. p 254. In: McComb JA, Hardy GE St.J., Tommerup IC (eds). 2nd International IUFRO Working Party 7.02.09 Meeting, Albany, W. Australia. Murdoch University. 297p

Harlow WM, Harrar ES (1969) Textbook of dendrology. McGraw-Hill, New York, p 512

Hibbert-Frey H, Frampton J, Balzich FA, Hinesley LE (2010) Grafting Fraser fir (Abies fraseri): effect of grafting date, shade, and irrigation. HortSci 45:617-620

Hinesley E, Frampton J (2002) Grafting Fraser fir onto rootstock of selected Abies species. HortSci 37:815-818

Holmes KA, Benson DM (1994) Evaluation of Phytophthora parasitica var. nicotianae as a biocontrol for Phytophthora parasitica on Catharanthus roseus. Plant Dis 78:193-199

Krüssmann G (1995) Manual of cultivated conifers. Timber Press, Portland, p 361

Liu T-S (1971) A monograph of the genus Abies. Tapei. Department of Forestry, National Taiwan University. 608 p.

Rushforth, K (1987) Conifers. Facts on File, Inc. New York. 608p

SAS System for Windows (2009) SAS/Stat software, version 9.2. SAS Institute Inc. Cary, NC, USA

Shew HD, Benson DM (1982) Fraser fir root rot induced by Phytophthora citricola. Plant Dis 65:688-689

Stejskal J, Kobliha J, Frampton J (2011) Results of Czech-American cooperation in interspecific fir hybridization in 2008 and 2009. Czech J For Sci 57:114-122

Strickland R (2007) U.S. Department of Agriculture, Economic Research Services. Amber waves-did you know? Bull. 19. Available: http://www.ers.usda.gov/AmberWaves/February08/PDF/ DidYouKnow.pdf via the Internet. Accessed 19 July 2011

Sturrock RN, Frankel SJ, Brown AV, Hennon PE, Kliejunas JT, Lewis $\mathrm{KJ}$, Worrall JJ, Woods AJ (2011) Climate change and forest diseases. Plant Pathol 60:133-149

van Gelderen DM, van Hoey Smith JRP (1995) Conifers, 2nd edn. Timber Press, Portland, p 269

Zentmyer GA (1988) Origin and distribution of four species of Phytophthora. Trans Br Mycol Soc 91:367-378 